\title{
Acute lower respiratory infections in $\geq 5$ year -old hospitalized patients in Cambodia, a low-income tropical country: clinical characteristics and pathogenic etiology
}

Sirenda Vong ${ }^{1 *}$, Bertrand Guillard', Laurence Borand', Blandine Rammaert ${ }^{1}$, Sophie Goyet ${ }^{1}$, Vantha Te², Patrich Lorn Try ${ }^{3}$, Sopheak Hem', Sareth Rith', Sowath Ly ${ }^{1}$, Philippe Cavailler', Charles Mayaud ${ }^{4}$ and Philippe Buchy ${ }^{1}$

\begin{abstract}
Background: Few data exist on viral and bacterial etiology of acute lower respiratory infections (ALRI) in $\geq 5$ year-old persons in the tropics.

Methods: We conducted active surveillance of community-acquired ALRI in two hospitals in Cambodia, a low-income tropical country. Patients were tested for acid-fast bacilli (AFB) by direct sputum examination, other bacteria by blood and/or sputum cultures, and respiratory viruses using molecular techniques on nasopharyngeal/ throat swabs. Pulmonologists reviewed clinical/laboratory data and interpreted chest X-rays (CXR) to confirm ALRI.

Results: Between April 2007 - December 2009, 1,904 patients aged $\geq 5$ years were admitted with acute pneumonia (50.4\%), lung sequelae-associated ALRI (24.3\%), isolated pleural effusions (8.9\%) or normal CXR-related ALRI (17.1\%); $61(3.2 \%)$ died during hospitalization. The two former diagnoses were predominantly due to bacterial etiologies while viral detection was more frequent in the two latter diagnoses. AFB-positive accounted for $25.6 \%$ of acute pneumonia. Of the positive cultures (16.8\%), abscess-prone Gram-negative bacteria (39.6\%) and Haemophilus influenzae (38.0\%) were most frequent, followed by Streptococcus pneumoniae (17.7\%). Of the identified viruses, the three most common viruses included rhinoviruses (49.5\%), respiratory syncytial virus (17.7\%) and influenza viruses (12.1\%) regardless of the diagnostic groups. Wheezing was associated with viral identification (31.9\% vs. 13.8\%, $p<0.001)$ independent of age and time-to-admission.
\end{abstract}

Conclusions: High frequency of H. influenzae and S. pneumoniae infections support the need for introduction of the respective vaccines in the national immunization program. Tuberculosis was frequent in patients with acute pneumonia, requiring further investigation. The relationship between respiratory viruses and wheezing merits further studies.

Keywords: Cambodia, Acute lower respiratory infection, Tropics, Hospitalized patients, Viruses, Bacteria, Adults, Older children

\footnotetext{
* Correspondence: sirenda.vong@gmail.com

${ }^{1}$ Institut Pasteur in Cambodia, Réseau International des Instituts Pasteur, Phnom Penh, Cambodia

Full list of author information is available at the end of the article
} 


\section{Background}

Pneumonia and other acute lower respiratory infections (ALRI) are the third leading cause of death worldwide and the first in low-income countries [1]. The vast majority of ALRI deaths are due to pneumonia [1] and nearly all severe ALRI episodes occur in children under 5 years, the elderly and immuno-compromised individuals (e.g. HIV-infected). Globally, approximately 4.2 million deaths caused by ALRI are estimated to occur annually across all age groups [2]. ALRI is a disease of all ages in low-income countries; it is one of the most common diagnoses upon admission [3].

Despite this burden and the development of improved microbiological molecular methods, only few recent studies with well characterized ALRI, clinical diagnoses in which bacterial and viral testing have been additionally performed have been published [4-7]. In general, the etiology of ALRI, and pneumonia in particular, remains difficult to establish $[8,9]$ using either insensitive or non-specific indirect methods such as blood culture, diagnostic serology and pathogenic detection of the upper airway [10]. In many low-income countries, most hospital laboratories do not possess the capacity for microbiologic diagnostic testing and pneumonia is still defined clinically using radiographs which are not always available in many health facilities. Taken together, the epidemiology of ALRI remains poorly defined across the developing world.

We collaborated with two Cambodian provincial hospitals to determine the etiology of community-acquired ALRI. This report summarizes the microbiological, radiological and clinical findings with a focus on patients aged 5 years and older.

\section{Methods}

\section{Study site and study population}

Cambodia (estimated 2008 population 14.6 Million) [11] is a tropical country in Southeast Asia. The country has very poor health indicators with life expectancy at birth of 59 years and an infant mortality of 90.9/1,000 live births [11]. The study hospitals were located in Takeo province (estimated population 0.9 Million) and Kampong Cham province (estimated pop. 1.7 Million) [11], both within $\sim 150 \mathrm{~km}$ of Phnom Penh, the capital. Like most Cambodian public hospitals, the selected study hospitals were ill-equipped with poor laboratory capacity for microbial identification, possessed no CT scanners, and had inadequate intensive care units (supplemental oxygen available but no mechanical ventilation).

\section{Study design}

We enrolled patients aged $\geq 5$ years hospitalized with a clinical syndrome compatible with ALRI, which was defined as (1) symptom onset $\leq 14$ days AND (2) a fever of $\geq 38^{\circ} \mathrm{C}$ or a history of febrile episodes during the last 3 days AND (3) cough, AND at least one of the following respiratory symptom or signs: dyspnea, chest pain, or crackles on lung auscultation. Patients with known tuberculosis (TB), HIV or active cancer were excluded. Decision whether to hospitalize was left to the clinicians' judgment. Demographic information, basic clinical features, past medical history and use of antibiotics prior to admission were collected on a standardized case report form (CRF). Recorded laboratory and microbiology findings, antibiotic treatment and outcome status upon discharge were also collected. Independent expert pulmonologists unaware of the microbiologic diagnosis retrospectively interpreted each CXR. They subsequently assigned the final diagnosis of the various types of ALRI in this study based on a combination of the CXR interpretation and information from the CRF. Written informed consent was obtained from patients aged 18 years and older and the parents or guardians of children. The study was approved by the Cambodian National Ethical Committee for Medical Research.

\section{Specimen collection}

Blood cultures, non-induced sputum samples, and throat and nasopharyngeal swabs (Tubed Sterile Dryswab ${ }^{\circledR}$ cotton-tip) were to be all collected from each participant within 48 hours after hospital presentation for direct examination, culture and molecular diagnostic testing. Cultures and molecular techniques were performed at the Institut Pasteur - Cambodia (IPC) in Phnom Penh. Blood Hemoline Diphasic Performance culture bottles (BioMérieux) were stored in an incubator at $37^{\circ} \mathrm{C}$. The incubator was provided by the surveillance project and was transported daily along with sputum which had been collected in the preceding 12 hours. Swabs were immediately placed in a viral transport medium after collection, which was containers consisting of frozen liquid nitrogen. As part of the National Tuberculosis Control Program, direct sputum examination for acidfast bacilli (AFB) testing was performed on admission and repeated during the subsequent two days in the hospital laboratories. White cell counts and blood chemistries were also performed in the hospital laboratories. The provider-initiated testing and counseling policy was initiated in 2007 in Cambodia. This policy integrates routine HIV testing for patients with sexually transmitted infections or TB, pregnant women, and hospitalized patients suspected of being infected with HIV (per the National HIV/AIDS program; http://www.nchads.org).

\section{Microbiology testing}

All nasopharyngeal and throat samples were tested using 5 validated multiplex reverse transcription polymerase chain reaction (RT-PCR)/PCR for the presence of 18 viral 
respiratory pathogens including human metapneumovirus, respiratory syncytial virus (RSV), human bocavirus, Influenza A and B viruses, coronaviruses (OC43, 229E, HKU-1, NL63, SARS), parainfluenza viruses 1-4, adenoviruses, rhinovirus and enteroviruses, as previously described elsewhere $[12,13]$. Sputum specimens were stained using the May-Grünwald-Giemsa method. Only good-quality specimens were submitted for bacterial cultures (defined as $>25$ polynuclear leukocytes and $<25$ squamous epithelial cells per low-power field) [14]. Sputum specimens were inoculated on colistin-nalidixic acid agar (CNA), cystinelactose-electrolyte-deficient agar (CLED), chocolate polyvitex agar with bacitracin, and Ashdown agar. Bacterial isolates were identified by API gallery (BioMérieux).

\section{Case definitions}

A bacteriological diagnosis was confirmed when a pathogen was isolated from an uncontaminated blood culture or sputum specimen obtained on admission. A significant growth of bacteria was defined as greater than $10^{7}$ organisms per $\mathrm{ml}$ of original sputum. TB infection was defined by a positive acid-fast-bacilli (AFB) smear, as $97 \%$ of them were linked to a positive culture for Mycobacterium tuberculosis in Cambodian hospitalized patients (IPC's unpublished data). Three external expert pulmonologists concurred that a severe case would be defined by the presence of at least 2 of the following criteria: systolic blood pressure $<90 \mathrm{mmHg}$, heart rate $\geq 120$ beats per minute, respiratory rate $\geq 30 / \mathrm{min}$, oxygen saturation $<90 \%$ measured by pulse oximeter, body temperature $\angle 35^{\circ} \mathrm{C}$ or $\geq 40^{\circ} \mathrm{C}$; international severity indices (e.g. PSI or CURB65) for pneumonia could not be applied in absence of ICUs or blood urea testing. Pneumonia was defined by the radiologic images of lobar consolidation, nodules, alveolar or interstitial infiltrates; a necrotizing pneumonia meant presence of cavitations. Preexisting pulmonary lesions may alter or disguise the appearance of a pneumonic infiltrate. Consequently we created a separate diagnostic group, ALRI with lung sequelae which was defined as radiological images of cavitary sequelae, partial collapse or bronchiectasis. The ALRI with the normal parenchyma group consisted of patients presenting with symptoms of acute bronchitis and normal lung radiographs.

\section{Data analysis}

We included reliable clinical signs and symptoms, major laboratory findings, reports of medical history, antibiotic use during and preceding hospitalization, and the final diagnosis provided by the pulmonology experts in our analysis. Statistical differences between various groups were detected using either Chi-squared or adjusted Chi-squared test, Chi-squared for trend test, and non-parametric (Kruskal-Wallis) test as appropriate. Proportions, odds ratios (OR), adjusted ORs (aOR) and p values were calculated using STATA version 9.0 (Stata corp., College Station, TX, USA). We used the Mantel-Haenszel test for bivariate analysis and the Wald test in the logistic regression model retaining variables with a $\mathrm{p}$ value of $\leq 0.1$.

\section{Results}

\section{Patient characteristics}

During April 2007 - December 2009, of 2,193 hospitalized patients aged $\geq 5$ years who met the eligibility criteria, 1,904 patients were confirmed to have a diagnosis of ALRI and their data were analyzed (Figure 1). The demographic characteristics of the patients and their diagnoses are presented in Table 1.

\section{Microbiological etiology}

While nasopharyngeal/throat swabs (97.4\%) and blood samples (89.0\%) could be easily obtained for each patient, sputum samples were only able to be collected in 1,053 patients $(12.8 \%$ and $54.8 \%$ in $5-14$ year-olds and $>15$ yearolds respectively). Sputum was only available for culture in 888 (46.6\%) patients ranging from $21.9 \%$ among cases presenting with pleural effusions alone to $64.0 \%$ among pneumonia cases. In contrast, sputum specimens were more readily available for direct AFB examination. This major gap was mainly explained by incorrect sputum specimen collection that resulted in salivary contamination (monthly mean rate $13.2 \%$, range: $5.3 \%-23.9 \%$ ). Overall, a combination of these tests identified bacterial and viral etiology in 749 (42.9\%) patients ranging from $8.8 \%$ positive results in patients with pleural effusions alone to $69.8 \%$ in patients with necrotizing pneumonia (Table 1). Mixed infections were not associated with severity ( $\mathrm{p}=0.192$ ) or a specific type of ALRI, except between the groups of necrotizing pneumonia and non-cavitary pneumonia $(7.3 \%$ versus $1.6 \%, \mathrm{p}<0.001)$ (Table 1$)$. Of the identified pathogens, bacteria (73.9\%) were the most frequent etiology in pneumonia with predominantly AFB (41.2\%; $67.7 \%$ in necrotizing pneumonia and $21.5 \%$ in non-cavitary pneumonia), followed by Haemophilus influenzae (9.8\%) and Streptococcus pneumoniae (4.5\%) (Figure 2). Bacteria also predominated in lung sequelaeassociated ALRI (67.9\%) consisting of $H$. influenzae (21.1\%), AFB (19.3\%), Gram-negative bacteria (11.0\%) and S. pneumoniae (10.6\%). In contrast, a viral etiology was predominant in ALRI patients with a normal CXR (67.5\%) including the pleural effusions group (54.5\%) and ALRI with normal CXR group (74.3\%) (Figure 1).

Of the 300 (16.8\%) positive sputum or blood cultures, abscess-prone Gram-negative bacteria (39.6\%) (i.e. Klebsiella pneumoniae, Burkholderia pseudomallei, Pseudomonas aeruginosa) and $H$. influenzae (38.0\%) were most frequent, followed by $S$. pneumoniae (17.7\%). Of the 305 identified viruses, the three most common viruses included rhinoviruses (49.5\%), respiratory syncytial virus (17.7\%), influenza viruses 


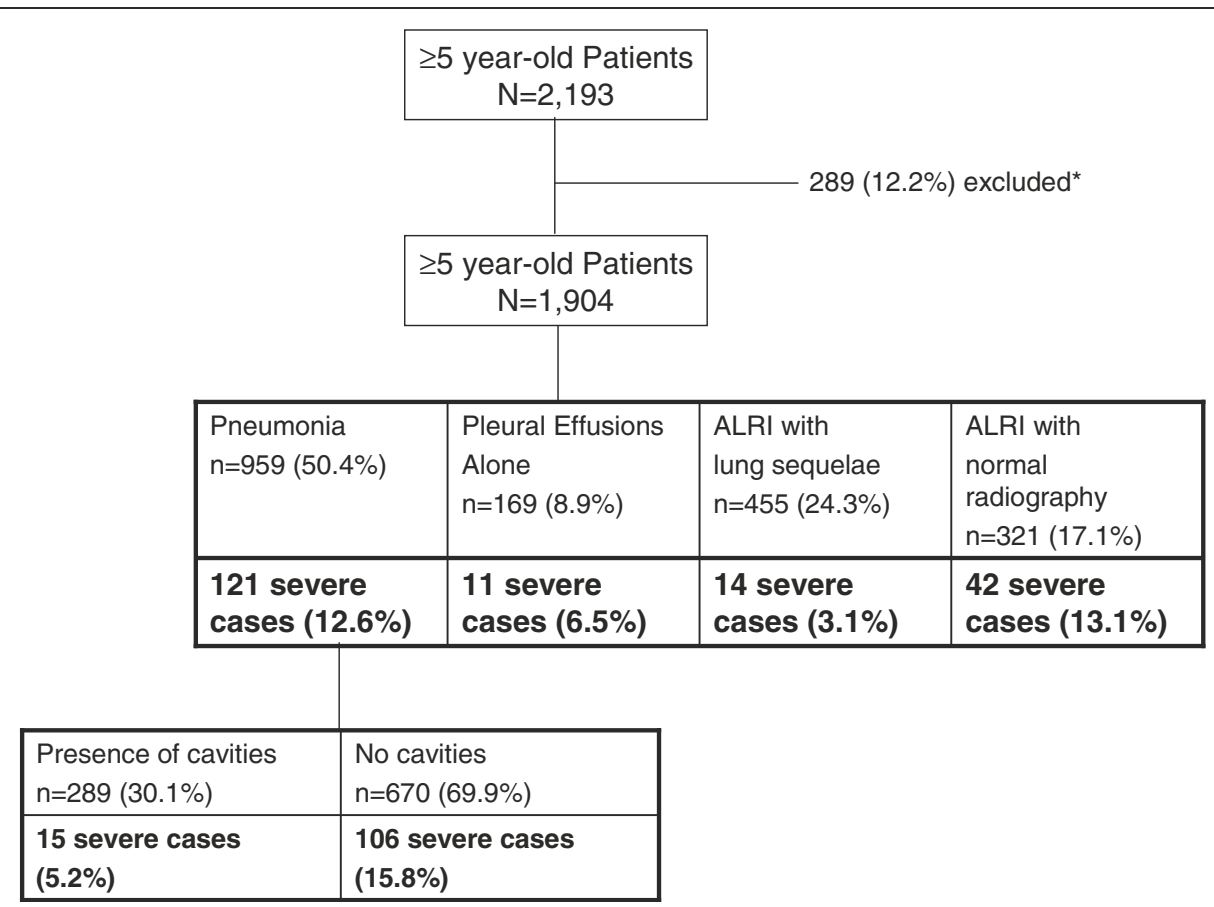

Figure 1 Various clinical diagnostic groups among patients aged $\geq 5$ years and hospitalized with acute lower respiratory infection, Kampong Cham and Takeo provinces, Cambodia, April 2007 - December 2009. *Reasons for exclusion: absence of chest X-ray (11.4\%); patients ascertained as having extra-pulmonary diseases (9.9\%) or upper-respiratory infections (0.5\%); 8 patients who also had extra-pulmonary site of infection and those who reported a history of hospitalization within the 2 preceding weeks.

(12.1\%) and coronaviruses (10.2\%), regardless of the diagnostic groups (Table 1).

\section{Mortality and severity}

During hospitalization, 61 (3.2\%) patients died, of which the following etiologic agents were identified in 22 (36.1\%) patients including 7 (31.8\%) with Burkholderia pseudomallei, 3 with AFB, 3 with various bacteria, 7 with viruses (including 5 rhinoviruses alone) and 2 with mixed infections. The median age of the deceased patients was 50 years (range: $6-87$ ). When compared to patients who improved at discharge, those with who died in hospital were more likely to have B. pseudomallei infection $(4.1 \%$ vs. $31.8 \%, \mathrm{p}<0.001)$, diagnosis of pneumonia ( $45.3 \%$ vs. $70.5 \%, \mathrm{p}<0.001)$, and elevated blood neutrophils count (34.7\% vs. $49.2 \%, \mathrm{p}=0.024)$; no differences were observed in gender, age, with co-morbid conditions, and in combination with other pathogens.

A total of 188 (9.8\%) patients met the criteria for severe cases, of which the most frequent signs consisted of tachycardia (77.7\%), tachypnea (93.1\%) and low oxygen saturation (39.4\%). Pneumonia with (8.0\%) and without (56.4\%) cavitations and ALRI with normal CXR (22.3\%) accounted for the majority of the severe cases. When compared with non-severe cases, severe cases tended to be younger (median age 25.5 years vs. 55 years, $\mathrm{P}<0.001$ ); $42.6 \%$ of the severe cases were aged 5-15 years and the median age of severe cases in the non-cavitary pneumonia group was 8 years (Table 1). Other univariate analyses of differences between severe and non-severe cases are illustrated in Table 2. Multivariate analyses revealed the following variables independently associated with severity: $<50$ years of age (69.1\% vs. $39.8 \%$; adjusted OR (aOR) $2.9, \mathrm{p}<0.001)$, elevated blood neutrophil count (56.4\% vs. $32.9 \%$; aOR 2.0, $\mathrm{p}=0.001)$, non-cavitary pneumonia (56.4\% vs. $32.9 \%$; aOR $3.6, \mathrm{p}<0.001)$, mortality (9.0\% vs. $2.6 \%$; aOR $3.2, \mathrm{p}=0.002)$, shorter ( $<5$ days) time to admission $(62.8 \%$, aOR $2.0, \mathrm{p}=$ $0.005)$ and wheezing (33.5\% vs. $11.5 \%$, aOR 2.5, p $<0.001)$ (Table 3).

Overall, 261 (13.7\%) patients presented with wheezing on admission of which $63(24.1 \%)$ were classified as severe cases. Among the 5-14 year-olds, $63.4 \%$ had wheezing compared with $11.1 \%$ in the $>50$ year age group. The frequency of wheezing was significantly higher in acute bronchitis (32.8\%) compared with other diagnostic groups. Other independent variables that were observed with wheezing included having an elevated-neutrophil-count (19.4\% vs. $10.7 \%$; aOR $1.8, \mathrm{p}=0.001$ ), being diagnosed with a rhinovirus infection ( $32.7 \%$ vs. $12.4 \%$; aOR $2.7, \mathrm{p}<0.001$ ) and being classified as a severe case $(33.5 \%$ vs. $11.7 \%$; aOR 2.3, $\mathrm{p}<0.001)$. Notably, asthma as a co-morbid condition was insufficiently recorded in the CRF; only 17 (0.9\%) asthmatic patients were reported and 1,510 (79.3\%) CRF had missing values. 
Table 1 Characteristics of 1904 patients aged $\geq 5$ years hospitalized with community-acquired acute lower respiratory infection from April 2007 to December 2009, Kampong Cham and Takeo provinces, Cambodia

\begin{tabular}{|c|c|c|c|c|c|c|c|c|c|c|c|c|}
\hline & \multirow[b]{2}{*}{ Grand total } & \multicolumn{3}{|c|}{ Pneumonia [1] } & \multirow{2}{*}{$\begin{array}{l}\text { Pleural Effusions } \\
\text { alone [2] } \\
\text { n (\%) }\end{array}$} & \multirow{2}{*}{$\begin{array}{c}\text { ALRI with } \\
\text { sequelae [3] } \\
\text { n (\%) }\end{array}$} & \multirow{2}{*}{$\begin{array}{c}\text { ALRI with } \\
\text { normal CXR [4] } \\
\text { n (\%) }\end{array}$} & \multicolumn{5}{|c|}{$\begin{array}{l}\text { P values from comparisons between } \\
\text { group [1], [2], [3] and [4] by } \\
\text { Chi-squared or adjusted Chi-squared test }\end{array}$} \\
\hline & & Total & $\begin{array}{l}\text { Cavitations } \\
{[1 \mathrm{a}]}\end{array}$ & $\begin{array}{c}\text { No cavitations } \\
{[1 \mathrm{~b}]}\end{array}$ & & & & $\begin{array}{l}\text { [1a] vs. } \\
{[1 \mathrm{~b}]}\end{array}$ & $\begin{array}{l}\text { [1] vs. } \\
{[2]}\end{array}$ & $\begin{array}{c}\text { [1] vs. } \\
{[3]}\end{array}$ & $\begin{array}{l}\text { [1] vs. } \\
{[4]}\end{array}$ & $\begin{array}{l}\text { [3] vs. } \\
{[4]}\end{array}$ \\
\hline & $1904(\%)$ & $959(50.4)$ & $289(30.1)$ & $670(69.9)$ & $169(8.9)$ & $455(24.3)$ & $321(17.1)$ & & & & & \\
\hline Median age in years (IQR*) & $53(38-65)$ & 51 & 50 & $52(35-65)$ & $52(40-66)$ & $60(51-70)$ & $44(17-59)$ & NS & NS & $<0.001$ & $<0.001$ & $<0.001$ \\
\hline Mean age in years & 50.0 & 48.6 & 49.3 & 48.3 & 51.0 & 59.0 & 40.5 & NS & NS & $<0.001$ & $<0.001$ & $<0.001$ \\
\hline \multicolumn{13}{|l|}{ Age groups in years } \\
\hline $5-14$ & $154(8.1 \%)$ & $82(8.6)$ & $0(0.0)$ & $82(12.2)$ & $3(1.8)$ & $1(0.2)$ & $68(21.2)$ & $<0.001$ & $<0.001$ & $<0.001$ & $<0.001$ & $<0.001$ \\
\hline $15-49$ & $659(34.6 \%)$ & $368(38.4)$ & $144(49.8)$ & $224(33.4)$ & $72(42.6)$ & $97(21.3)$ & $122(38.0)$ & $<0.001$ & NS & $<0.001$ & NS & $<0.001$ \\
\hline$\geq 50$ & $1091(57.3)$ & $509(53.1)$ & $145(50.2)$ & $364(54.3)$ & $94(55.6)$ & $357(78.5)$ & $131(40.8)$ & 0.249 & NS & $<0.001$ & $<0.001$ & $<0.001$ \\
\hline Gender, male (\%) & $941(49.4)$ & $502(52.3)$ & $157(54.3)$ & $345(51.5)$ & $90(53.3)$ & $205(45.1)$ & $144(44.9)$ & NS & NS & 0.011 & 0.026 & NS \\
\hline \multicolumn{13}{|l|}{$\begin{array}{l}\text { Signs and symptoms on } \\
\text { admission }\end{array}$} \\
\hline Wheezing & $261(13.9)$ & $105(11.1)$ & $13(4.5)$ & $92(14.0)$ & $3(1.8)$ & $50(11.0)$ & $103(32.8)$ & $<0.001$ & $<0.001$ & NS & $<0.001$ & $<0.001$ \\
\hline Dry cough & $519(27.3)$ & $229(23.9)$ & $39(13.5)$ & $190(28.4)$ & $111(65.7)$ & $66(14.5)$ & $113(35.2)$ & $<0.001$ & $<0.001$ & $<0.001$ & $<0.001$ & $<0.001$ \\
\hline \multicolumn{13}{|c|}{$\begin{array}{l}\text { Time interval between } \\
\text { presentation and symptoms onset } \\
\text { in days (\# of missing values }=112 \text { ) }\end{array}$} \\
\hline Median (IQR) & $6(4-9)$ & $6(4-9)$ & $7(4-10)$ & $5(4-9)$ & $6(4-10)$ & $6(4-10)$ & $4(4-8)$ & $<0.001$ & NS & 0.032 & 0.004 & $<0.001$ \\
\hline Mean & 6.3 & 6.3 & 7.0 & 5.9 & 6.6 & 6.7 & 5.6 & $<0.002$ & NS & 0.072 & 0.003 & $<0.001$ \\
\hline \multicolumn{13}{|c|}{ Duration of hospital stay in days } \\
\hline Median (IQR) & $7(4-11)$ & $7(4-10)$ & $6(4-10)$ & $7(4-10)$ & $5(3-8)$ & $9(6-14)$ & $7(4-10)$ & NS & $<0.001$ & $<0.001$ & NS & $<0.001$ \\
\hline Mean & 8.4 & 7.9 & 7.8 & 8 & 6.5 & 10.7 & 7.7 & NS & $<0.001$ & $<0.001$ & NS & $<0.001$ \\
\hline \multicolumn{13}{|c|}{$\begin{array}{l}\text { Reports of medicine use prior to } \\
\text { admission }\end{array}$} \\
\hline No antibiotic used & $932(48.9)$ & $455(47.4)$ & $116(40.1)$ & $339(50.6)$ & $103(60.9)$ & $211(46.4)$ & $163(50.8)$ & 0.004 & 0.002 & NS & NS & NS \\
\hline Intake of unknown origin & $776(40.8)$ & $405(42.2)$ & $143(49.5)$ & $262(39.1)$ & $43(25.4)$ & $211(46.4)$ & $117(36.4)$ & 0.004 & $<0.001$ & NS & 0.078 & 0.013 \\
\hline Antibiotic used & $196(10.3)$ & $99(10.3)$ & $30(10.4)$ & $69(10.3)$ & $23(13.6)$ & $33(7.3)$ & $41(12.8)$ & NS & NS & 0.087 & NS & 0.014 \\
\hline \multicolumn{13}{|l|}{ Patient outcomes } \\
\hline Deceased & $61(3.2)$ & $43(4.5)$ & $6(2.1)$ & $37(5.5)$ & $5(3.0)$ & $11(2.4)$ & $2(0.6)$ & 0.021 & NS & 0.076 & 0.003 & NS \\
\hline Cured or improved & $1264(66.4)$ & $572(59.6)$ & $117(40.5)$ & 455 (67.9) & 79 (46.7) & $321(70.5)$ & $292(91.0)$ & $<0.001$ & 0.002 & $<0.001$ & $<0.001$ & $<0.001$ \\
\hline Transferred & $482(25.3)$ & $297(31.0)$ & $154(53.3)$ & $143(21.3)$ & $82(48.5)$ & 89 (19.6) & $14(4.4)$ & $<0.001$ & $<0.001$ & $<0.001$ & $<0.001$ & $<0.001$ \\
\hline Escaped & $97(5.1)$ & $47(4.9)$ & $12(4.2)$ & $35(5.2)$ & $3(1.8)$ & $34(7.5)$ & $13(4.0)$ & NS & NS & 0.066 & NS & 0.031 \\
\hline
\end{tabular}


Table 1 Characteristics of 1904 patients aged $\geq 5$ years hospitalized with community-acquired acute lower respiratory infection from April 2007 to December 2009, Kampong Cham and Takeo provinces, Cambodia (Continued)

\begin{tabular}{|c|c|c|c|c|c|c|c|c|c|c|c|c|}
\hline \multicolumn{13}{|l|}{ Reported co-morbid conditions } \\
\hline Cardiovascular disorder & $213(11.2)$ & $129(13.5)$ & $9(3.1)$ & $120(17.9)$ & $17(10.1)$ & $28(6.2)$ & $39(12.1)$ & $<0.001$ & NS & $<0.001$ & NS & 0.003 \\
\hline Diabetes mellitus & $195(10.2)$ & $111(11.6)$ & $32(11.1)$ & 79 (11.8) & $22(13.0)$ & $40(8.8)$ & $22(6.9)$ & NS & NS & NS & 0.023 & NS \\
\hline Renal disorder & $136(7.1)$ & $80(8.3)$ & $25(8.7)$ & $55(8.2)$ & $8(4.7)$ & $33(7.3)$ & $15(4.7)$ & NS & NS & NS & 0.044 & NS \\
\hline Liver disorder & $16(0.8)$ & $10(1.0)$ & $3(1.0)$ & $7(1.0)$ & $3(1.8)$ & $1(0.2)$ & $2(0.6)$ & NS & NS & NS & NS & NFS \\
\hline Severe cases & $188(9.9)$ & $121(12.6)$ & $15(5.2)$ & $106(15.6)$ & $11(6.5)$ & $14(3.1)$ & $42(13.1)$ & $<0.001$ & 0.032 & $<0.001$ & NS & $<0.001$ \\
\hline \multicolumn{13}{|l|}{ Laboratory results** } \\
\hline Leukocytosis (missing values $=12$ ) & $663(34.8)$ & $399(41.9)$ & $120(41.7)$ & $279(42.2)$ & $42(25.3)$ & $133(29.4)$ & $89(27.8)$ & NS & $<0.001$ & $<0.001$ & $<0.001$ & NS \\
\hline $\begin{array}{l}\text { Elevated neutrophils count } \\
\text { (missing values }=65 \text { ) }\end{array}$ & $629(33.0)$ & $378(40.9)$ & $114(40.6)$ & $264(41.1)$ & $40(24.4)$ & $127(28.9)$ & $84(27.0)$ & NS & $<0.001$ & $<0.001$ & $<0.001$ & NS \\
\hline $\begin{array}{l}\text { Lymphocytosis } \\
\text { (missing values = 314) }\end{array}$ & $99(5.2)$ & $46(5.5)$ & $7(3.0)$ & $39(6.4)$ & $8(5.0)$ & $22(7.7)$ & $23(7.5)$ & 0.004 & NS & NS & NS & NS \\
\hline \multicolumn{13}{|l|}{$\begin{array}{l}\text { Patients tested by microbiology } \\
\text { method (excluding contaminated } \\
\text { samples or cultures) }\end{array}$} \\
\hline Blood culture & $1695(89.0)$ & $862(89.9)$ & $264(91.3)$ & $598(89.3)$ & $149(88.2)$ & $412(90.5)$ & $272(84.7)$ & NS & NS & NS & 0.015 & 0.012 \\
\hline Sputum culture & $888(46.6)$ & $464(48.4)$ & $185(64.0)$ & $279(41.6)$ & $37(21.9)$ & $270(59.3)$ & $117(36.4)$ & $<0.001$ & $<0.001$ & $<0.001$ & 0.002 & $<0.001$ \\
\hline Blood or sputum culture & $1789(94.0)$ & 905 (94.4) & $280(96.9)$ & 625 (93.3) & $152(89.9)$ & $437(96.0)$ & $295(91.9)$ & NS & NS & NS & NS & 0.016 \\
\hline $\begin{array}{l}\text { Sputum smear for acid-fast bacilli } \\
\text { (AFB) }\end{array}$ & $1682(88.3)$ & $850(88.6)$ & $280(96.9)$ & $570(85.1)$ & $140(82.8)$ & $434(95.4)$ & $258(80.4)$ & NS & NS & $<0.001$ & 0.001 & $<0.001$ \\
\hline $\begin{array}{l}\text { Nasopharyngeal/throat swabs by } \\
\text { PCR (a) }\end{array}$ & $1855(97.4)$ & $935(97.5)$ & $281(97.2)$ & $654(97.6)$ & $164(97.0)$ & $442(97.1)$ & $314(97.8)$ & NS & NS & NS & NS & NS \\
\hline $\begin{array}{l}\text { Samples collected for bacterial \& } \\
\text { AFB etiologies (b) }\end{array}$ & $1796(94.3)$ & $911(95.0)$ & $283(97.9)$ & $628(93.7)$ & $152(89.9)$ & $438(96.3)$ & $295(91.9)$ & NS & NS & NS & NS & 0.008 \\
\hline $\begin{array}{l}\text { Samples collected for bacterial \& } \\
\text { viral etiologies (c) }\end{array}$ & $1747(91.8)$ & $887(92.5)$ & $275(95.2)$ & $612(91.3)$ & $147(87.0)$ & $425(93.4)$ & $288(89.7)$ & NS & NS & NS & NS & 0.064 \\
\hline \multicolumn{13}{|l|}{ Bacterial or viral yield $\neq$} \\
\hline Positive blood culture & $33(2.0)$ & $27(3.1)$ & $5(1.9)$ & $22(3.7)$ & $4(2.7)$ & $2(0.5)$ & $0(0.0)$ & NS & NS & 0.007 & 0.007 & NS \\
\hline Positive sputum culture & $272(30.6)$ & $138(29.7)$ & $44(23.8)$ & $94(33.7)$ & $8(21.6)$ & $95(35.2)$ & $31(26.5)$ & 0.029 & NS & NS & NS & NS \\
\hline $\begin{array}{l}\text { Positive blood or sputum culture } \\
\text { (d) }\end{array}$ & $300(16.8)$ & $161(17.8)$ & 47 (16.8) & $114(18.2)$ & $12(7.9)$ & $96(22.0)$ & $31(10.5)$ & NS & 0.003 & 0.079 & 0.007 & $<0.001$ \\
\hline Positive AFB smear (e) & $264(15.7)$ & $218(25.7)$ & $153(54.6)$ & $65(11.4)$ & $2(1.4)$ & $42(9.7)$ & $2(0.8)$ & $<0.001$ & $<0.001$ & $<0.001$ & $<0.001$ & $<0.001$ \\
\hline Positive PCR for viruses ( $f$ ) & $305(16.4)$ & $138(14.8)$ & $22(7.8)$ & $116(17.7)$ & $17(10.4)$ & $68(15.4)$ & $82(26.1)$ & $<0.001$ & NS & NS & $<0.001$ & 0.004 \\
\hline
\end{tabular}


Table 1 Characteristics of 1904 patients aged $\geq 5$ years hospitalized with community-acquired acute lower respiratory infection from April 2007 to December 2009, Kampong Cham and Takeo provinces, Cambodia (Continued)

\begin{tabular}{|c|c|c|c|c|c|c|c|c|c|c|c|c|}
\hline \multicolumn{13}{|l|}{ Bacterial etiologiest } \\
\hline H. influenzae & $114(38.0)$ & $52(32.3)$ & $13(27.7)$ & $39(34.2)$ & $0(0.0)$ & $46(47.9)$ & $16(51.6)$ & NS & 0.005 & 0.002 & NS & 0.022 \\
\hline - In sputum ${ }^{1}$ & $114(41.9)$ & $52(37.7)$ & $13(29.5)$ & $39(41.5)$ & $0(0.0)$ & $46(48.4)$ & $16(51.6)$ & & & & & \\
\hline$-\ln$ blood $^{2}$ & $1(3.0)$ & $1(3.7)$ & $1(20.0)$ & $0(0.0)$ & $0(0.0)$ & $0(0.0)$ & $0(0.0)$ & & & & & \\
\hline S. pneumoniae & $53(17.7)$ & $22(13.7)$ & $6(12.8)$ & $16(14.0)$ & $1(8.3)$ & $23(24.0)$ & $7(22.6)$ & NS & NS & 0.009 & NS & NS \\
\hline - In sputum ${ }^{1}$ & $51(18.8)$ & $20(14.5)$ & $6(13.6)$ & $14(14.9)$ & $1(12.5)$ & $23(24.2)$ & $7(22.6)$ & & & & & \\
\hline$-\ln$ blood $^{2}$ & $2(6.0)$ & $2(7.4)$ & $0(0.0)$ & $2(9.1)$ & $0(0.0)$ & $0(0.0)$ & $0(0.0)$ & & & & & \\
\hline B. pseudomallei & $28(9.3)$ & $25(15.5)$ & $10(21.3)$ & $15(13.2)$ & $1(8.3)$ & $1(1.0)$ & $1(3.2)$ & NS & NS & $<0.001$ & 0.020 & NS \\
\hline - In sputum ${ }^{1}$ & $16(5.9)$ & $14(10.1)$ & $7(15.9)$ & $7(7.4)$ & $1(12.5)$ & $0(0.0)$ & $1(3.2)$ & & & & & \\
\hline- In blood ${ }^{2}$ & $15(45.5)$ & $14(51.9)$ & $4(9.0)$ & $10(10.6)$ & $0(0.0)$ & $1(1.1)$ & $0(0.0)$ & & & & & \\
\hline K. pneumoniae & $43(14.3)$ & $28(17.4)$ & $10(21.3)$ & $18(15.8)$ & $2(16.7)$ & $8(8.3)$ & $5(16.1)$ & NS & NS & NS & NS & NS \\
\hline - In sputum ${ }^{1}$ & $42(15.4)$ & $27(19.6)$ & $10(22.7)$ & $17(18.1)$ & $2(25.0)$ & $8(8.4)$ & $5(16.1)$ & & & & & \\
\hline$-\ln$ blood $^{2}$ & $1(3.0)$ & $1(3.7)$ & $0(0.0)$ & $1(4.6)$ & $0(0.0)$ & $0(0.0)$ & $0(0.0)$ & & & & & \\
\hline P. aeruginosa & $37(12.3)$ & 19 (11.8) & $6(12.8)$ & $13(11.4)$ & $1(8.3)$ & $15(15.6)$ & $2(6.5)$ & NS & NS & NS & NS & 0.037 \\
\hline S. aureus & $11(3.7)$ & $5(3.1)$ & $2(4.3)$ & $3(2.6)$ & $1(8.3)$ & $4(4.2)$ & $1(3.2)$ & NS & NS & NS & NS & NS \\
\hline Other bacteria & $39(13.0)$ & $22(13.7)$ & $4(8.5)$ & $18(15.8)$ & $7(58.3)$ & $9(9.4)$ & $1(3.2)$ & NS & NS & NS & 0.040 & NS \\
\hline AFB-positive ${ }^{* * *}$ & $264(15.7)$ & $218(25.6)$ & $153(54.6)$ & $65(11.4)$ & $2(1.4)$ & $42(9.7)$ & $2(0.8)$ & $<0.001$ & $<0.001$ & $<0.001$ & $<0.001$ & $<0.001$ \\
\hline \multicolumn{13}{|l|}{ Positive PCR results $\wedge$} \\
\hline Rhinovirus & $151(49.5)$ & $68(49.3)$ & $10(45.5)$ & $58(50.0)$ & $8(47.1)$ & $30(44.1)$ & $45(54.9)$ & 0.007 & NS & NS & $<0.001$ & 0.001 \\
\hline Respiratory syncytial virus & $54(17.7)$ & $23(16.7)$ & $5(23.7)$ & $18(15.5)$ & $5(29.4)$ & $11(16.2)$ & $15(18.3)$ & NS & NS & NS & 0.064 & NS \\
\hline Influenza viruses & $37(12.1)$ & $16(11.6)$ & $3(13.6)$ & $13(11.2)$ & $0(0.0)$ & $11(16.2)$ & $10(12.2)$ & NS & NS & NS & NS & NS \\
\hline Coronaviruses & $31(10.2)$ & $18(13.0)$ & $2(9.9)$ & $16(13.8)$ & $1(5.9)$ & $11(16.2)$ & $1(1.2)$ & NS & NS & NS & 0.080 & 0.001 \\
\hline Human metapneumovirus & $14(4.6)$ & $7(5.1)$ & $0(0.0)$ & $7(6.0)$ & $2(11.8)$ & $2(2.9)$ & $3(3.7)$ & NS & NS & NS & NS & NS \\
\hline Other viruses & $20(6.6)$ & $6(4.3)$ & $2(9.1)$ & $4(3.5)$ & $2(11.8)$ & $5(7.4)$ & $7(8.5)$ & NS & NS & NS & NS & NS \\
\hline \multicolumn{13}{|l|}{ Mixed infections } \\
\hline $\begin{array}{l}>1 \text { pathogen (AFB, bact. or virus) } \\
\left(\%=\mathrm{n}^{*} 100 / \mathrm{d}\right)\end{array}$ & $63(21.0)$ & $35(21.7)$ & $16(34.0)$ & $19(16.7)$ & $2(16.7)$ & $22(22.9)$ & $4(12.9)$ & NS & NS & NS & NS & NS \\
\hline $\begin{array}{l}>1 \text { bacterium identified }(\%= \\
\left.\mathrm{n}^{*} 100 / \mathrm{d}\right)\end{array}$ & $24(8.0)$ & $12(7.5)$ & $4(8.5)$ & $8(7.0)$ & $0(0.0)$ & $10(10.4)$ & $2(6.5)$ & NS & NS & NS & NS & NS \\
\hline $\begin{array}{l}\text { AFB and } \geq 1 \text { bacterium identified } \\
\left(\%=n^{*} 100 / d\right)\end{array}$ & $30(10.0)$ & $24(14.9)$ & $16(34.0)$ & $8(7.0)$ & $0(0.0)$ & $6(6.3)$ & $0(0.0)$ & NS & NS & NS & NS & NS \\
\hline AFB \& virus $\left(\%=n^{*} 100 / f\right)$ & $26(8.5)$ & $18(13.0)$ & $14(63.6)$ & $4(3.5)$ & $0(0.0)$ & $8(11.8)$ & $0(0.0)$ & 0.005 & NS & NS & NS & NS \\
\hline$>1$ virus $\left(\%=n^{*} 100 / f\right)$ & $9(3.0)$ & $3(2.2)$ & $1(4.5)$ & $2(1.7)$ & $2(1.7)$ & $2(2.9)$ & $2(2.4)$ & NS & NS & NS & NS & NS \\
\hline
\end{tabular}


Table 1 Characteristics of 1904 patients aged $\geq 5$ years hospitalized with community-acquired acute lower respiratory infection from April 2007 to December 2009, Kampong Cham and Takeo provinces, Cambodia (Continued)

\begin{tabular}{|c|c|c|c|c|c|c|c|c|c|c|c|c|}
\hline \multicolumn{13}{|l|}{ Overall etiology results } \\
\hline 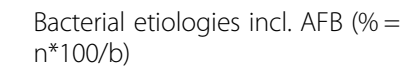 & $520(29.0)$ & $355(39.0)$ & $184(65.0)$ & $171(27.2)$ & $0(0.0)$ & $132(30.1)$ & $33(11.2)$ & $<0.001$ & $<0.001$ & 0.002 & $<0.001$ & $<0.001$ \\
\hline Viral detection $\left(\%=n^{*} 100 / a\right)$ & $298(16.1)$ & $135(14.4)$ & $21(7.5)$ & $114(17.4)$ & $13(7.9)$ & $68(15.4)$ & $82(26.1)$ & NS & 0.033 & NS & $<0.001$ & NS \\
\hline Identified etiologies $\left(\%=n^{*} 100 / c\right)$ & 749 (42.9) & $449(50.6)$ & $192(69.8)$ & $257(42.0)$ & $13(8.8)$ & $178(41.9)$ & 109 (37.8) & $<0.001$ & $<0.001$ & 0.004 & $<0.001$ & $<0.001$ \\
\hline
\end{tabular}

IQR: interquartile range; NS, not significant (NS is displayed when $\mathrm{p}$ value is $>10 \%$ ); PCR, polymerase chain reaction;

$A L R I=$ acute lower respiratory infection; Other viruses include Parainfluenza viruses, Bocaviruses, Adenoviruses.

**Hyperleukocytosis: Leukocytes count $\geq 11$ for $5-10$ year-olds or $\geq 10$ for $\geq 11$ year-olds.

**Elevated neutrophils count $\geq 6$ for $5-10$ year-olds or $\geq 7.5$ for $\geq 11$ year-olds.

*** \% = proportion of AFB-positive by \# of patients tested for AFB.

₹ \%= proportion of positive results by \# of patients tested.

$\dagger \%=$ proportion of positive bacteria by \# of patients tested positive by sputum or blood culture.

1 and ${ }^{2} \%=$ proportion of positive bacteria by \# of patients tested positive by sputum and blood culture respectively.

$\wedge \%=$ proportion of virus of interest by \# of positive PCR. 


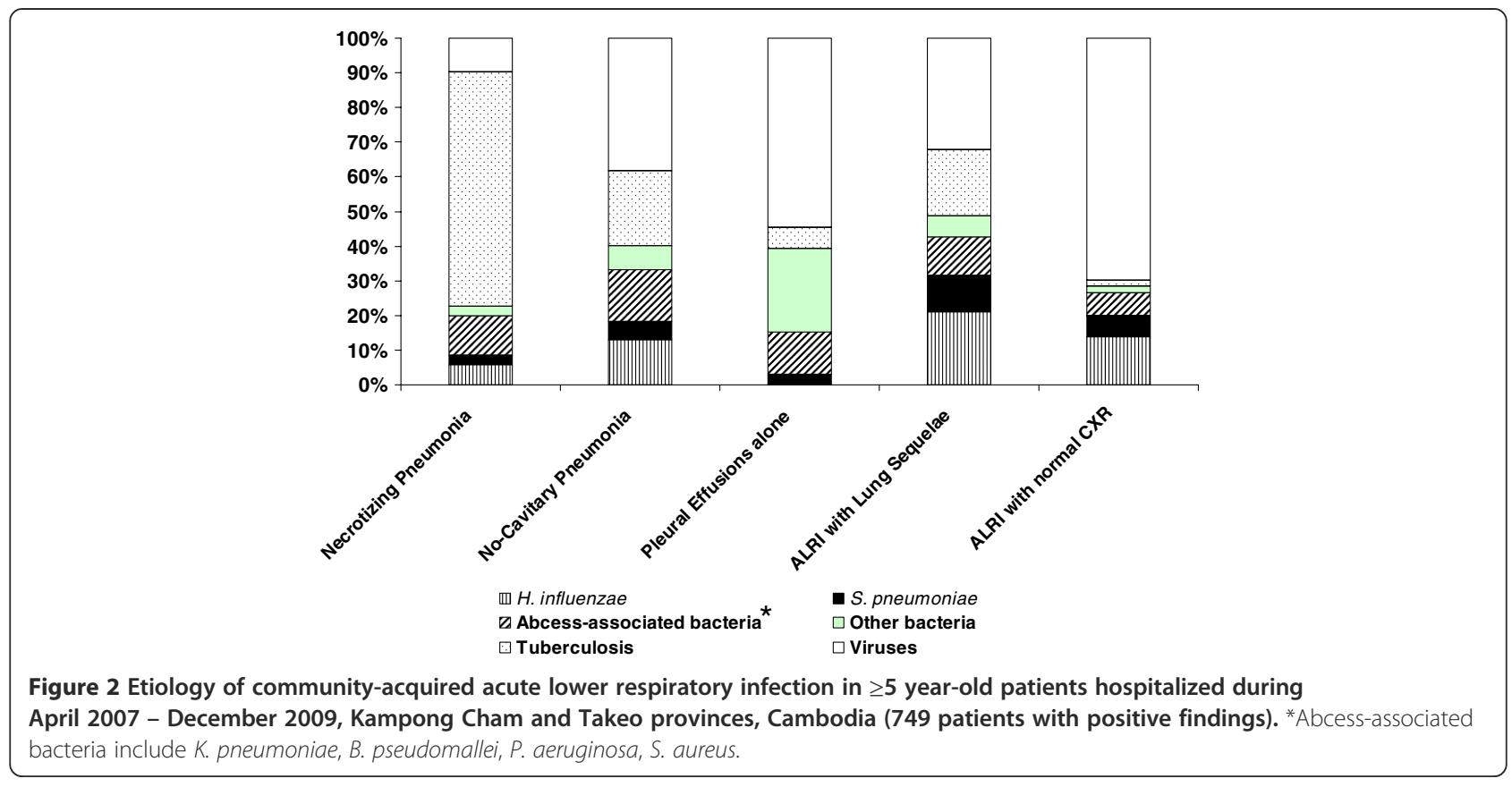

Factors associated with identification of microorganisms Age was significantly associated with microbiological yield. The proportion of patients with identifiable viruses among those presenting with pneumonia (Chi-squared test for trend 76.3, $\mathrm{p}<0.001$ ) or those with ALRI and normal CXR (Chi-squared test for trend 16.5, $\mathrm{p}<0.001$ ) decreased with increasing age while proportions of patients with identified bacteria were higher among the $\geq 10$ year-olds compared with that of the $<10$ year-olds (17.6\% versus $4.3 \%$ respectively, $\mathrm{p}=0.002)$. Most patients (51.1\%) reported use of antibiotics $(10.3 \%)$ or unknown drugs $(40.8 \%)$ prior to hospital admission. No associations were observed between pre-admission antibiotic use and negative sputum $(\mathrm{p}=0.854)$ or blood $(\mathrm{p}=0.275)$ culture. When considering the influence of other factors for virus identification in a multivariate analysis, wheezing (31.9\% vs. $13.8 \%$, aOR 2.2, p < 0.001), 5-14 year-old children (54.6\% vs. $14.0 \%$; aOR $1.6, \mathrm{p}=0.001)$ and short ( $<5$ days) time to admission (22.6\% vs. $11.5 \%$; aOR 1.9 , $\mathrm{p}<0.001$ ) had a positive association with viral yield. Of all detected viruses, only rhinovirus was associated with wheezing (32.7\% vs. $12.3 \%$, aOR $2.7, \mathrm{p}<0001$ ), adjusting for age.

Interestingly, of the 796 patients whose blood and sputum specimens were negative for bacteria, 121 (15.2\%) patients presented with an elevated blood lymphocyte count or normal neutrophil count on admission; these 121 patients had no radiographic images indicative of $\mathrm{TB}$, no necrotizing pneumonia, and no use of antibiotics preceding hospitalization. The median age was 55 years (range 6 - 85) and 50.4\% were males. Viral etiology was assigned to $28(21.6 \%)$ patients including rhinoviruses
(35.7\%), RSV (42.9\%), influenza viruses (14.3\%) and parainfluenza viruses $(7.1 \%)$. Of these, 9 were diagnosed as having pneumonia (i.e. 4 rhinoviruses, 3 influenza viruses and 2 RSV), 10 had lung sequelae-associated ALRI (i.e. 5 RSV, 3 rhinoviruses, 1 influenza virus, 1 parainfluenza virus), 2 had pleural effusions alone (i.e. 2 RSV) and 7 had acute bronchitis (i.e. 1 parainfluenza virus, 3 RSV and 3 rhinoviruses). Of the 5 (3.7\%) reported deceased, only one virus (RSV) was identified in a 53 yearold male presenting with severe non-cavitary pneumonia and no reported co-morbid conditions.

\section{Discussion}

This study is notable in many ways. To our knowledge, it is the first report of a comprehensive picture of radiographically confirmed pneumonia and other ALRI that resulted in hospitalization in a low-income tropical country of Southeast Asia. In addition, only a few studies have been conducted in semi-rural hospitals in a population of all ages using a wide range of diagnostic tools to identify viruses and bacteria causing ALRI [5-7,15,16].

The primary finding relates to categorizing various forms of ALRI based on radiographic patterns combined with the identification of pathogens. Indeed, bacterial etiologies varied significantly from one form of ALRI to another. Pneumonia, which is mainly caused by bacteria in hospitalized persons aged $\geq 5$ years, accounted for most of the ALRI cases. However, a large proportion of the ALRI patients had radiographic imaging of lung sequelae, most probably caused by tuberculosis or undertreated pneumonia.

Depending on the immune response of the host, TB generally evolves slowly (3-8 weeks) before the onset of 
Table 2 Univariate analyses: factors associated with severity among $\geq \mathbf{5}$ year-old patients hospitalized with communityacquired acute lower respiratory infection, April 2007 - December 2009, Kampong Cham and Takeo provinces, Cambodia $(\mathrm{N}=1,904)$

\begin{tabular}{|c|c|c|c|c|c|}
\hline & Severe cases & & Non-severe cases & & $p$ values \\
\hline Total numbers $(\mathrm{N}=1904)$ & 188 & $9.9 \%$ & 1716 & $90.1 \%$ & \\
\hline Median age in years (range) & 25.5 & $8-56$ & 55 & $41-66$ & $<0.001$ \\
\hline Mean age in years & 32.1 & & 51.8 & & $<0.001$ \\
\hline \multicolumn{6}{|l|}{ Age groups in years } \\
\hline $5-14$ & 80 & $42.6 \%$ & 74 & $4.3 \%$ & $<0.001$ \\
\hline $15-49$ & 50 & $26.6 \%$ & 609 & $35.5 \%$ & 0.019 \\
\hline$\geq 50$ & 58 & $30.9 \%$ & 1033 & $60.2 \%$ & $<0.001$ \\
\hline Gender, male & 106 & $56.4 \%$ & 835 & $48.7 \%$ & 0.068 \\
\hline \multicolumn{6}{|l|}{ Signs and symptoms } \\
\hline Wheezing & 63 & $33.5 \%$ & 198 & $11.5 \%$ & $<0.001$ \\
\hline Dry cough & 84 & $44.7 \%$ & 435 & $25.3 \%$ & $<0.001$ \\
\hline
\end{tabular}

Time interval between presentation and symptoms onset in days

Median (IQR)

Duration of hospital stay in days

Median (IQR)

Mean

4
4.9

$2-7$

9

5

6.1

Reports of medicine use prior to admission

$$
\begin{aligned}
& \text { no antibiotics used } \\
& \text { Unidentified drugs used } \\
& \text { Antibiotics used }
\end{aligned}
$$

Patient outcomes

Deceased
Cured or improved
Transferred
Escaped

\section{Co-morbidities}

Cardiovascular disorder

Diabetes mellitus

Renal disorder

Liver disorder

Laboratory results

$$
\begin{aligned}
& \text { Leukocytosis } \\
& \text { Neutrocytosis } \\
& \text { Lymphocytosis }
\end{aligned}
$$$$
97
$$$$
62
$$

Patients tested by microbiology method

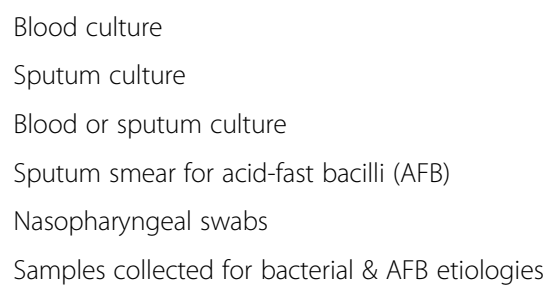

$$
\text { 3-7 }
$$

$51.6 \%$

$33.0 \%$

$15.4 \%$

$9.0 \%$

$70.2 \%$

$17.0 \%$

$3.7 \%$

$14.9 \%$

$10.6 \%$

$9.6 \%$

$0.0 \%$

$57.3 \%$

$58.6 \%$

$8.5 \%$

$89.4 \%$

$25.0 \%$

$92.0 \%$

$60.1 \%$

$97.9 \%$

$92.0 \%$
6

6.4

7

8.6

835

714

154

\section{4}

1132

450

90

190

175

113

16

552

523

85

1527

843

1616

1569

1671

1623
4-9

$<0.001$

$<0.001$

4-11

$<0.001$

$<0.001$

$48.7 \%$

NS

$41.6 \%$

0.028

0.007

$9.0 \%$

$2.6 \%$

$66.0 \%$

$<0.001$

NS

$26.2 \%$

0.008

$5.2 \%$

NS

NS

NS

NS

NS

$0.9 \%$

$32.3 \%$

$<0.001$

$<0.001$

NS

$5.6 \%$

$89.0 \%$

NS

$49.1 \%$

0.002

$94.2 \%$

NS

$91.4 \%$

$<0.001$

$97.4 \%$

$94.6 \%$ 
Table 2 Univariate analyses: factors associated with severity among $\geq 5$ year-old patients hospitalized with communityacquired acute lower respiratory infection, April 2007 - December 2009, Kampong Cham and Takeo provinces, Cambodia $(\mathrm{N}=1,904)$ (Continued)

\begin{tabular}{|c|c|c|c|c|c|}
\hline Samples collected for bacterial \& viral etiologies & 169 & $89.9 \%$ & 1579 & $92.0 \%$ & NS \\
\hline \multicolumn{6}{|l|}{ Bacterial or viral yield } \\
\hline Positive blood culture & 9 & $5.4 \%$ & 24 & $1.6 \%$ & 0.002 \\
\hline Positive sputum culture & 15 & $31.9 \%$ & 257 & $30.5 \%$ & NS \\
\hline Positive blood or sputum culture & 24 & $13.9 \%$ & 276 & $17.1 \%$ & NS \\
\hline Positive smear for AFB & 13 & $11.5 \%$ & 251 & $16.0 \%$ & $<0.001$ \\
\hline Positive PCR for viruses & 55 & $29.9 \%$ & 250 & $15.0 \%$ & $<0.001$ \\
\hline \multicolumn{6}{|l|}{ Bacterial etiologies } \\
\hline H. influenzae & 5 & $2.9 \%$ & 109 & $6.7 \%$ & 0.074 \\
\hline S. pneumoniae & 3 & $1.7 \%$ & 50 & $3.1 \%$ & NS \\
\hline B pseudomallei & 5 & $2.9 \%$ & 23 & $1.4 \%$ & NS \\
\hline Klebsiella pneumoniae & 5 & $2.9 \%$ & 38 & $2.4 \%$ & NS \\
\hline P. aeroginosa & 1 & $0.6 \%$ & 36 & $2.2 \%$ & NS \\
\hline S. aureus & 1 & $0.6 \%$ & 10 & $0.6 \%$ & NS \\
\hline AFB & 13 & $7.5 \%$ & 251 & $15.5 \%$ & 0.030 \\
\hline \multicolumn{6}{|l|}{ Viral etiologies } \\
\hline Rhinovirus & 32 & $17.4 \%$ & 119 & $7.1 \%$ & $<0.001$ \\
\hline Respiratory syncytial virus & 6 & $3.3 \%$ & 48 & $2.9 \%$ & NS \\
\hline Influenza viruses & 4 & $2.2 \%$ & 33 & $2.0 \%$ & NS \\
\hline Coronaviruses & 6 & $3.3 \%$ & 25 & $1.5 \%$ & NS \\
\hline Human metapneumovirus & 4 & $2.2 \%$ & 10 & $0.6 \%$ & 0.054 \\
\hline Other viruses & 5 & $2.7 \%$ & 21 & $1.3 \%$ & NS \\
\hline \multicolumn{6}{|l|}{ Mixed infections ( $\%=\#$ of the positive results) } \\
\hline$>1$ pathogen (AFB, bacterium or virus) & 3 & $3.5 \%$ & 60 & $8.9 \%$ & NS \\
\hline$>1$ bacterium identified & 1 & $1.2 \%$ & 25 & $3.7 \%$ & NS \\
\hline AFB and $\geq 1$ bacterium identified & 1 & $1.2 \%$ & 29 & $4.3 \%$ & NS \\
\hline Co-infections AFB \& virus & 0 & $0.0 \%$ & 26 & $3.9 \%$ & NS \\
\hline Co-infections virus-virus & 2 & $2.3 \%$ & 6 & $0.9 \%$ & NS \\
\hline \multicolumn{6}{|l|}{ Overall etiology results } \\
\hline Bacterial etiologies (AFB or other bacteria) & 36 & $20.8 \%$ & 498 & $30.7 \%$ & $<0.001$ \\
\hline Viral and bacterial etiologies & 86 & $50.9 \%$ & 674 & $42.7 \%$ & $<0.001$ \\
\hline
\end{tabular}

symptoms $[17,18]$. However, in this study, we were surprised to have found AFB to be the most common pathogen in hospitalized patients with acute pneumonia. Although Cambodia is known as one of the countries with the highest TB prevalence and incidence reported in the world (http://www.who.int/tb/country/en/index.html), the interpretation of these results is unclear. It is possible that the history of illness was poorly recalled by the patient or a mixed infection existed with a non-TB respiratory pathogen which may have led to hospitalization. On the other hand, there is emerging evidence across the world and particularly shown in African studies, that $M$. tuberculosis is commonly present in acute communityacquired pneumonia in children [15,19] and adults [20], particularly in settings of high TB prevalence. One suggested explanation is the increased susceptibility to bacterial infection (particularly pneumococcal infection) by prior M. tuberculosis infection as demonstrated by experimental studies [21]. In the present study, $21 \%$ of tuberculosis cases were co-infected with other bacteria, of which S. pneumoniae was the main (43\%) pathogen identified. Our findings imply that expanding the TB screening criteria to include acute pneumonia might be considered. Of note, Cambodia is planning to develop a multi-symptoms 
Table 3 Independent risk factors for severe community-acquired acute lower respiratory infection among hospitalized $\geq 5$ year-old patients, from April 2007 to December 2009, Kampong Cham and Takeo provinces, Cambodia

\begin{tabular}{|c|c|c|c|c|c|c|}
\hline & \multicolumn{2}{|c|}{ Severe cases } & \multicolumn{2}{|c|}{ Non-severe cases } & \multirow[b]{2}{*}{ Adjusted $O R^{*}$} & \multirow[b]{2}{*}{ p value } \\
\hline & $\mathrm{N}=188$ & $\%$ & $N=1716$ & $\%$ & & \\
\hline \multicolumn{7}{|l|}{ Age groups } \\
\hline $5-49$ years & 130 & $69.1 \%$ & 683 & $39.8 \%$ & 2.9 & $<0.001$ \\
\hline$>50$ years & 58 & $30.9 \%$ & 1033 & $60.2 \%$ & reference & \\
\hline \multicolumn{7}{|l|}{ Pneumonia } \\
\hline No cavities & 106 & $56.4 \%$ & 564 & $32.9 \%$ & reference & \\
\hline With cavities & 15 & $8.0 \%$ & 274 & $16.0 \%$ & 0.33 & 0.029 \\
\hline Pleurisy alone & 11 & $5.9 \%$ & 158 & $9.2 \%$ & 0.51 & 0.133 \\
\hline Sequelae prior infection & 14 & $7.4 \%$ & 441 & $25.7 \%$ & 0.21 & $<0.001$ \\
\hline ALRI with normal CXR & 42 & $22.3 \%$ & 279 & $16.3 \%$ & 0.52 & 0.018 \\
\hline \multicolumn{7}{|l|}{ Neutrophils } \\
\hline Normal & 75 & $39.9 \%$ & 1063 & $61.9 \%$ & reference & \\
\hline Elevated & 106 & $56.4 \%$ & 523 & $30.5 \%$ & 2.03 & 0.001 \\
\hline \multicolumn{7}{|l|}{ Outcome } \\
\hline Improved & 132 & $70.2 \%$ & 1132 & $66.0 \%$ & reference & \\
\hline Deceased & 17 & $9.0 \%$ & 44 & $2.6 \%$ & 3.20 & 0.002 \\
\hline \multicolumn{7}{|l|}{ Wheezing } \\
\hline No & 125 & $66.5 \%$ & 1494 & $87.1 \%$ & reference & \\
\hline Yes & 63 & $33.5 \%$ & 198 & $11.5 \%$ & 2.50 & $<0.001$ \\
\hline \multicolumn{7}{|l|}{ Time to admission } \\
\hline$<5$ days & 118 & $62.8 \%$ & 653 & $38.1 \%$ & 2.00 & \\
\hline$\geq 5$ days & 65 & $34.6 \%$ & 984 & $57.3 \%$ & reference & 0.005 \\
\hline
\end{tabular}

*Adjusted by viral etiology, bacterial etiology, antibiotics intake prior admission, time to admission and gender.

**B By Wald test.

approach to increase cost-effective routine screening for TB.

Our second main finding also indicates that a nonnegligible proportion of patients presenting with cavitary lung imaging suggestive of TB were affected by other abscessassociated bacteria (e.g. K. pneumoniae, B. pseudomallei, S. aureus, etc... .). Prior to this study, these bacteria tended not to be recognized by local clinicians who empirically treated patients with a penicillin A-based therapy, an antibiotic that is not effective on some naturally resistant strains of Gram-negative bacteria such as B. pseudomallei [22,23]. In adult patients with non-cavitary pneumonia, common pathogens causing community-acquired pneumonia in West and Far-East Asia include S. pneumoniae, Mycoplasma pneumoniae, Chlamydia pneumoniae and Legionella pneumoniae [15,16,24-26]. First, atypical pathogens (i.e. C. pneumoniae and M. pneumoniae) were rarely detected in our hospitalized patients: of a subgroup of sputum specimens from a group of 304 randomly selected study patients, only 3 tested positive by PCR: 2 for M. pneumoniae and 1 for C. pneumoniae (IPC, unpublished data). This result was also observed elsewhere $[20,27,28]$ and was consistent with another recent study of community-acquired pneumonia among immunocompromised adults in Cambodia [27]. Secondly, we found a lower frequency of $S$. pneumoniae compared with other bacteria. Because $S$. pneumoniae is known to be fragile, some related infections might have gone undetected as cultures were performed at IPC after a certain delay due to transportation of specimens [29]. The extent of undetected S. pneumoniae infection may be suggested by the following sub-study: of a random sample of 24 ALRI cases (median 58 years of age, range $18-78$ ) for which we also collected urine samples, three (13\%, 95\% confidence interval 3\% - 32\%) patients tested positive for S. pneumoniae antigen by Binax $\mathrm{NOW}^{\circledR}$ rapid immunochromatographic assay (Scarborough, ME). (IPC, unpublished data). Accounting for this underestimation, one might expect $S$. pneumoniae or $H$. influenzae -related respiratory infections to reach $\sim 60 \%$ of the bacterial etiology of acute pneumonia. As a Global Alliance Vaccine Initiative or GAVI eligible country, Cambodia introduced $H$. influenzae $b$ vaccines in 2010 and will probably do so in the near future for pneumococcal conjugate vaccine.

RSV and influenza viruses have been recognized as the leading causes of severe ALRI in infants and young 
children [30,31]. These viruses can also cause severe ALRI in certain at-risk groups. In our study, viral pathogens, especially rhinoviruses and RSV were not only limited to these high risk groups but were common in older children. Moreover, age was determined as a major confounding factor when identifying risks associated with viral etiologies. Only time-to-admission was independently associated with the viral identification rate, a finding that suggests that viral infections were under-detected in many bacterial ALRI patients who were admitted late in the course of illness [32].

The extent to which these viruses cause direct and severe ALRI is difficult to assess in our study, particularly in absence of a control group. Indeed, certain viruses were demonstrated to be associated with severe pneumonia [33]; however, detection of some respiratory viruses, especially rhinoviruses, was frequently found in non-ill or non-respiratory infected control groups when using highly sensitive molecular diagnostic techniques [13,33-39]. Interestingly we identified viruses in ALRI patients with little evidence of associated bacterial infection. Further virologic analyses would be worthwhile to determine the factors comparing pneumonia cases with no evidence of bacterial infection to those associated with superinfection.

Symptoms associated with severity as defined by the parameters of the study were highly prevalent in children; the reasons are unclear or potentially explained by several factors such as having acute pneumonia and/or underlying asthma. Interestingly, wheezing was also independently associated with viral respiratory infection. This relationship between viral infection, asthma (wheezing as its surrogate), and disease severity have been observed more recently. Indeed, recent studies suggest that respiratory infections caused by rhinoviruses or RSV in infancy can lead to the development of asthma at an older age [40,41], which could be exacerbated by viral infections $[34,42,43]$. Recognizing the high frequency of wheezing in children with pneumonia ( 62\%) and its association with hyperleucocytosis in our study, it is possible that asthma could either directly cause a severe case or lead indirectly to signs of severity via superinfection and subsequent pneumonia. Education programs designed to recognize asthmatic symptoms, teach management strategies, and encourage the prevention of asthma should be urgently implemented.

These preceding findings need to be interpreted in light of some major limitations. First, the rate of bacteria identification in this study was low compared to other studies using routine clinical diagnostic techniques [15,27,44]. Approximately $17 \%$ of bacterial diagnoses were achieved through the use of blood or sputum cultures. This relatively low yield contrasted with a much higher proportion of pneumonia-related patients $(\sim 40 \%)$ who had an elevated blood neutrophil count, a parameter that is indicative of bacterial infection. Various factors contributed to this low yield, including the probable high intake of antibiotics, which can be bought without a prescription and frequently are administered irrespective of the proper dosage and length in Cambodia [45]. Since there was only a one-time collection of sputum and blood for each patient, a high bacterial yield was not expected. Moreover, sputum tests, which are commonly used to diagnose pneumonia, may lack specificity without evocative clinical information, have poor sensitivity or are frequently contaminated by saliva or upper respiratory tract colonization. This resulted in having to discard numerous sputum specimens prior to culture in our study. The use of invasive procedures such as brochioalveolar lavage or sputum induction was difficult to introduce, particularly in children. Second, the burden of TB in this study was probably largely underestimated as cultures for $M$. tuberculosis were not performed [46].

\section{Conclusions}

Overall, introducing a bacteriological laboratory capacity for ALRI surveillance has proven to be a major investment in settings of limited resources and experiences, requiring sustained training and monitoring to ensure reliability and consistency. Despite these challenges, bacteriological testing provides useful insights and contributions to virologic surveillance [47] and above all, directly benefits patients' care and treatment.

\section{Competing interest}

All authors declared no competing interest.

\section{Authors' contributions}

Conceived and designed the study: SV, PB, BG and CM. Performed the study: BR, LB, PC, SL, SG. Clinical data collected: VT, PLT, BR. Analyzed the data: SV, SG, SL. Contributed reagents/materials/analysis tools: BG, SH, SR, PB. Wrote the paper: SV, PB. Critical review of the paper: All. Found funding: SV, PB. All authors read and approved the final manuscript.

\section{Acknowledgements}

We specifically acknowledge the patients for their participation to this study. We are grateful to Dr Phat, Dr Mam, Dr Me, Dr Ya, Dr Koy, Dr Teav, Dr Ke, Dr Phea, Dr Chroeng, Dr Kim, Dr Iv, Dr Kheang, Dr Phe, Dr Chhav, Dr Ean, Dr leang for their contribution to this study and for patients care. We are also grateful to Drs. Cecile Toper, Nomonde Mafuma, Mélanie Courouble and Guy Letellier for participating in the interpretation of chest radiographs and the reviews of some of the CRF.

The project received grants from the Surveillance and Investigation of epidemic situations in South-East Asia (SISEA) project, which was funded by the French Agency for Development (Agence Française de Développement, AFD). This surveillance project also received financial support from the US Department of Human and Health Services (US DHHS).

\section{Author details}

${ }^{1}$ Institut Pasteur in Cambodia, Réseau International des Instituts Pasteur, Phnom Penh, Cambodia. ${ }^{2}$ Takeo provincial hospital, Takeo, Cambodia. ${ }^{3}$ Kampong Cham provincial hospital, Kampong Cham, Cambodia. ${ }^{4} \mathrm{Hôpital}$ Tenon, Assistance Publique - Hôpitaux de Paris, Paris, France.

Received: 14 May 2012 Accepted: 14 February 2013

Published: 22 February 2013 


\section{References}

1. World Health Organization: The global burden of disease: 2004 update. Available from: http://www.who.int/healthinfo/global_burden_disease/ 2004_report_update/en/index.html. [accessed 7 November 2011].

2. Rudan I, Tomaskovic L, Boschi-Pinto C, Campbell H: Global estimate of the incidence of clinical pneumonia among children under five years of age. Bull World Health Organ 2004, 82:895-903.

3. Scott JA, Brooks WA, Peiris JS, Holtzman D, Mulholland EK: Pneumonia research to reduce childhood mortality in the developing world. J Clin Invest 2008, 118(4):1291-1300.

4. Michelow IC, Olsen K, Lozano J, Rollins NK, Duffy LB, Ziegler T, Kauppila J, Leinonen M, McCracken GH Jr: Epidemiology and clinical characteristics of community-acquired pneumonia in hospitalized children. Pediatrics 2004, 113(4):701-707.

5. Olsen SJ, Thamthitiwat S, Chantra S, Chittaganpitch M, Fry AM, Simmerman $J M$, Baggett HC, Peret TC, Erdman D, Benson R, Talkington D, Thacker $L$, Tondella ML, Winchell J, Fields B, Nicholson WL, Maloney S, Peruski LF, Ungchusak K, Sawanpanyalert P, Dowell SF: Incidence of respiratory pathogens in persons hospitalized with pneumonia in two provinces in Thailand. Epidemiol Infect 2010, 138(12):1811-1822.

6. Baggett HC, Chittaganpitch M, Thamthitiwat S, Prapasiri P, Naorat S, Sawatwong P, Ditsungnoen D, Olsen SJ, Simmerman JM, Srisaengchai P, Chantra S, Peruski LF, Sawanpanyalert P, Maloney SA, Akarasewi P: Incidence and epidemiology of hospitalized influenza cases in rural Thailand during the influenza A (H1N1)pdm09 pandemic, 2009-2010. PLoS One 2012, 7(11)::48609. doi:10.1371/journal.pone.0048609.

7. Fry AM, Lu X, Olsen SJ, Chittaganpitch M, Sawatwong P, Chantra S, Baggett $H C$, Erdman D: Human rhinovirus infections in rural Thailand: epidemiological evidence for rhinovirus as both pathogen and bystander. PLoS One 2011, 6(3):e17780.

8. Mulholland K: Perspectives on the burden of pneumonia in children. Vaccine 2007, 25(13):2394-2397.

9. Rudan I, Lawn J, Cousens S, Rowe AK, Boschi-Pinto C, Tomaskovic L, Mendoza W, Lanata CF, Roca-Feltrer A, Carneiro I, Schellenberg JA, Polasek O, Weber M, Bryce J, Morris SS, Black RE, Campbell H: Gaps in policyrelevant information on burden of disease in children: a systematic review. Lancet 2005, 365(9476):2031-2040.

10. Mizgerd JP: Acute lower respiratory tract infection. N Engl J Med 2008, 358(7):716-727.

11. Asian Development Bank: Cambodia - facts sheet. Available from: http:// www.adb.org/Documents/Fact_Sheets/CAM.pdf. [Accessed 22 June 2011].

12. Bellau-Pujol S, Vabret A, Legrand L, Dina J, Gouarin S, PetitjeanLecherbonnier J, Pozzetto B, Ginevra C, Freymuth F: Development of three multiplex RT-PCR assays for the detection of 12 respiratory RNA viruses. J Virol Methods 2005, 126(1-2):53-63.

13. Buecher C, Mardy S, Wang W, Duong V, Vong S, Naughtin M, Vabret A, Freymuth F, Deubel V, Buchy P: Use of a multiplex PCR/RT-PCR approach to assess the viral causes of influenza-like illnesses in Cambodia during three consecutive dry seasons. J Med Virol 2010, 82(10):1762-1772.

14. Murray PR, Washington JA: Microscopic and bacteriologic analysis of expectorated sputum. Mayo Clin Proc 1975, 50(6):339-344.

15. Song JH, Oh WS, Kang Cl, Chung DR, Peck KR, Ko KS, Yeom JS, Kim CK, Kim SW, Chang HH, Kim YS, Jung SI, Tong Z, Wang Q, Huang SG, Liu JW, Lalitha MK, Tan BH, Van PH, Carlos CC, So T: Asian Network for Surveillance of Resistant Pathogens Study Group. Epidemiology and clinical outcomes of community-acquired pneumonia in adult patients in Asian countries: a prospective study by the Asian network for surveillance of resistant pathogens. Int J Antimicrob Agents 2008, 31(2):107-114.

16. Ngeow YF, Suwanjutha S, Chantarojanasriri T, Wang F, Saniel M, Alejandria M, Hsueh PR, Ping-Ing L, Park SC, Sohn JW, Aziah AM, Liu Y, Seto WH, Ngan CC, Hadiarto M, Hood A, Cheong YM: An Asian study on the prevalence of atypical respiratory pathogens in community-acquired pneumonia. Int J Infect Dis 2005, 9(3):144-153.

17. Todar K: Mycobacterium tuberculosis and Tuberculosis. 2009. Available from: Online Textbook of Bacteriology website: http://www.textbookofbacteriology. net/ tuberculosis.html [accessed 7 November 2012].

18. Marais BJ, Gie RP, Schaaf HS, Hesseling AC, Obihara CC, Starke JJ, Enarson DA, Donald PR, Beyers N: The natural history of childhood intra-thoracic tuberculosis: a critical review of literature from the prechemotherapy era. Int J Tuberc Lung Dis 2004, 8:392-402.
19. Moore DP, Klugman KP, Madhi SA: Role of Streptococcus pneumoniae in hospitalization for acute community-acquired pneumonia associated with culture-confirmed Mycobacterium tuberculosis in children: a pneumococcal conjugate vaccine probe study. Pediatr Infect Dis J 2010, 29(12):1099-04.

20. Scott JA, Hall AJ, Muyodi C, Lowe B, Ross M, Chohan B, Mandaliya K, Getambu E, Gleeson E, Drobniewski F, Marsh K: Aetiology, outcome, and risk factors for mortality among adults with acute pneumonia in Kenya. Lancet 2000, 355(9211):1225-1230.

21. Pedrosa J, Saunders BM, Appelberg R, Orme IM, Silva MT, Cooper AM: Neutrophils play a protective nonphagocytic role in systemic Mycobacterium tuberculosis infection of mice. Infect Immun 2000, 68:577-583.

22. Overtoom R, Khieu V, Hem S, Cavailler P, Te V, Chan S, Lau P, Guillard B, Vong S: A first report of pulmonary melioidosis in Cambodia. Trans $R$ SoC Trop Med Hyg 2008, 102(Suppl 1):S21-S25.

23. Wuthiekanun V, Pheaktra N, Putchhat H, Sin L, Sen B, Kumar V, Langla S, Peacock SJ, Day NP: Burkholderia pseudomallei antibodies in children, Cambodia. Emerg Infect Dis 2008, 14(2):301-303.

24. Liu Y, Chen M, Zhao T, Wang H, Wang R, Cai B, Cao B, Sun T, Hu Y, Xiu Q, Zhou X, Ding X, Yang L, Zhuo J, Tang Y, Zhang K, Liang D, LV X, Li S, Liu Y, Yu Y, Wei Z, Ying K, Zhao F, Chen P, Hou X: Causative agent distribution and antibiotic therapy assessment among adult patients with community acquired pneumonia in Chinese urban population. BMC Infect Dis 2009, 9:31. 18.

25. Miyashita N, Fukano H, Mouri K, Fukuda M, Yoshida K, Kobashi Y, Niki Y, Oka $\mathrm{M}$ : Community-acquired pneumonia in Japan: a prospective ambulatory and hospitalized patient study. J Med Microbiol 2005, 54:395-400.

26. Johansson N, Kalin M, Tiveljung-Lindell A, Giske CG, Hedlund J: Etiology of community-acquired pneumonia: increased microbiological yield with new diagnostic methods. Clin Infect Dis 2010, 50(2):202-209.

27. Charles PG, Whitby M, Fuller AJ, Stirling R, Wright AA, Korman TM, Holmes PW, Christiansen PJ, Waterer GW, Pierce RJ, Mayall BC, Armstrong JG, Catton MG, Nimmo GR, Johnson B, Hooy M, Grayson ML, Australian CAP Study Collaboration: The etiology of community-acquired pneumonia in Australia: why penicillin plus doxycycline or a macrolide is the most appropriate therapy. Clin Infect Dis 2008, 46(10):1513-1521.

28. Lui G, Ip M, Lee N, Rainer TH, Man SY, Cockram CS, Antonio GE, Ng MH, Chan MH, Chau SS, Mak P, Chan PK, Ahuja AT, Sung JJ, Hui DS: Role of 'atypical pathogens' among adult hospitalized patients with communityacquired pneumonia. Respirology 2009, 14(8):1098-1105.

29. Siberry G, Brahmadathan KN, Pandian R, Lalitha MK, Steinhoff MC, John TJ: Comparison of different culture media and storage temperatures for the long-term preservation of Streptococcus pneumoniae in the tropics. Bull World Health Organ 2001, 79(1):43-47.

30. Nair H, Nokes DJ, Gessner BD, Dherani M, Madhi SA, Singleton RJ, O'Brien KL, Roca A, Wright PF, Bruce N, Chandran A, Theodoratou E, Sutanto A, Sedyaningsih ER, Ngama M, Munywoki PK, Kartasasmita C, Simões EA, Rudan I, Weber MW, Campbell H: Global burden of acute lower respiratory infections due to respiratory syncytial virus in young children: a systematic review and meta-analysis. Lancet 2010, 375(9725):1545-1555.

31. Nair H, Brooks WA, Katz M, Roca A, Berkley JA, Madhi SA, Simmerman JM, Gordon A, Sato M, Howie S, Krishnan A, Ope M, Lindblade KA, CarosoneLink P, Lucero M, Ochieng W, Kamimoto L, Dueger E, Bhat N, Vong S, Theodoratou E, Chittaganpitch M, Chimah O, Balmaseda A, Buchy P, Harris E, Evans V, Katayose M, Gaur B, O'Callaghan-Gordo C, Goswami D, Arvelo W, Venter M, Briese T, Tokarz R, Widdowson MA, Mounts AW, Breiman RF, Feikin DR, Klugman KP, Olsen SJ, Gessner BD, Wright PF, Rudan I, Broor S, Simões FA, Campbell H: Global burden of respiratory infections due to seasonal influenza in young children: a systematic review and metaanalysis. Lancet 2011, 378(9807):1917-1930.

32. Speizer FE, Horton S, Batt J, Slutsky AS: 'Respiratory diseases of adults'. In Disease Control Priorities in Developing Countries. 2nd edition. Edited by Jamison D, Breman J, Measham A, Alleyne G, Claeson M, Evans D, Jha P, Mills A, Musgrove P. New York: World Bank and Oxford University Press; 2006.

33. Hayden FG: Respiratory viral threats. Curr Opin Infect Dis 2006, 19(2):169-178.

34. Busse WW, Lemanske RF Jr, Gern JE: Role of viral respiratory infections in asthma and asthma exacerbations. Lancet 2010, 376(9743):826-834.

35. Falsey AR, Criddle MC, Walsh EE: Detection of respiratory syncytial virus and human metapneumovirus by reverse transcription polymerase chain 
reaction in adults with and without respiratory illness. J Clin Virol 2006, 35:46-50.

36. Jackson DJ: The role of rhinovirus infections in the development of early childhood asthma. Curr Opin Allergy Clin Immunol 2010, 10(2):133-138.

37. van Benten I, Koopman L, Niesters B, Hop W, van Middelkoop B, de Waal L, van Drunen K, Osterhaus A, Neijens H, Fokkens W: Predominance of rhinovirus in the nose of symptomatic and asymptomatic infants. Pediatr Allergy Immunol 2003, 14(5):363-370.

38. van Gageldonk-Lafeber AB, Heijnen ML, Bartelds Al, Peters MF, van der Plas SM, Wilbrink B: A case-control study of acute respiratory tract infection in general practice patients in the Netherlands. Clin Infect Dis 2005, 41:490-497.

39. van Kraaij $M G$, van Elden $L$, van Loon $A M$, Hendriksen $K A$, Laterveer $L$, Dekker AW, Nijhuis M: Frequent detection of respiratory viruses in adult recipients of stem cell transplants with the use of real-time polymerase chain reaction, compared with viral culture. Clin Infect Dis 2005, 40:662-669.

40. Jackson DJ, Johnston SL: The role of viruses in acute exacerbations of asthma. J Allergy Clin Immunol 2010, 125(6):1178-1187.

41. Künzli N, Kaiser R, Medina S, Studnicka M, Chanel O, Filliger P, Herry P, Horak F Jr, Puybonnieux-Texier V, Quénel P, Schneider J, Seethaler R, Vergnaud JC, Sommer H: Public-health impact of outdoor and traffic-related air pollution: a European assessment. Lancet 2000, 356(9232):795-801.

42. Becklake MR: Wheeze, asthma diagnosis and medication use in developing countries. Thorax 2005, 60(11):885-887.

43. Pauwels RA, Rabe KF: Burden and clinical features of chronic obstructive pulmonary disease (COPD). Lancet 2004, 364(9476):613-620.

44. Vray M, Germani Y, Chan S, Duc NH, Sar B, Sarr FD, Bercion R, Rahalison L, Maynard M, L'Her P, Chartier L, Mayaud C: Clinical features and etiology of pneumonia in acid-fast bacillus sputum smear-negative HIV-infected patients hospitalized in Asia and Africa. AIDS 2008, 22(11):1323-1332.

45. Moszynski P: Cambodia cracks down on illegal drug vendors in bid to counter antimalarial resistance. BMJ 2010, 340:c2622. doi:10.1136/bmj.c2622.

46. Behr MA, Warren SA, Salamon H, Hopewell PC, Ponce de Leon A, Daley CL, Small PM: Transmission of Mycobacterium tuberculosis from patients smear-negative for acid-fast bacilli. Lancet 1999, 353(9151):444-449.

47. Do AH, van Doorn HR, Nghiem MN, Bryant JE, Hoang TH, Do QH, Van TL, Tran TT, Wills B, Nguyen VC, Vo MH, Vo CK, Nguyen MD, Farrar J, Tran TH, de Jong MD: Viral etiologies of acute respiratory infections among hospitalized Vietnamese children in Ho Chi Minh City, 2004-2008. PLoS One 2011, 6(3):e18176.

doi:10.1186/1471-2334-13-97

Cite this article as: Vong et al:: Acute lower respiratory infections in $\geq 5$ year -old hospitalized patients in Cambodia, a low-income tropical country: clinical characteristics and pathogenic etiology. BMC Infectious Diseases 2013 13:97.

\section{Submit your next manuscript to BioMed Central and take full advantage of:}

- Convenient online submission

- Thorough peer review

- No space constraints or color figure charges

- Immediate publication on acceptance

- Inclusion in PubMed, CAS, Scopus and Google Scholar

- Research which is freely available for redistribution 